\title{
The Mechanism Insight Into the Inhibitory Effect of Artemisinin Sustained-release Inhibitors With Different Particle Sizes on Microcystis aeruginosa
}

\section{Zhiyun Jiang}

Hohai University

lixiao Ni (D20040051@hhu.edu.cn )

Hohai University

Xianglan Li

Hohai University

Chu Xu

Hohai University

Xuqing Chen

Wuxi Cyanobacteria Control Office

Shiyin Li

Nanjing Normal University

\section{Research Article}

Keywords: Allelochemical, Particle sizes, Optimal manufacture, Inhibitory mechanism, Antioxidant enzyme activity, Cell membrane damage

Posted Date: July 23rd, 2021

DOl: https://doi.org/10.21203/rs.3.rs-636883/v1

License: (c) (i) This work is licensed under a Creative Commons Attribution 4.0 International License.

Read Full License 


\title{
The mechanism insight into the inhibitory effect of artemisinin
} sustained-release inhibitors with different particle sizes on

\section{Microcystis aeruginosa}

\author{
Zhiyun Jiang ${ }^{1}$, Lixiao $\mathrm{Ni}^{1 *}$, Xianglan $\mathrm{Li}^{1}$, Chu Xu ${ }^{1}$, Xuqing Chen ${ }^{2}$, Shiyin $\mathrm{Li}^{3}$
}

${ }^{1}$ School of Environment, Hohai University, Nanjing 210098, China

${ }^{2}$ Cyanobacteria Management Office, Wuxi Water Conservancy Bureau, Wuxi 214071, China

${ }^{3}$ School of Environment, Nanjing Normal University, Nanjing 210023, China

"Correspondence: 20040051@hhu.edu.cn

Highlights

1. Algicide with nanometer size were successfully prepared for algae inhibition.

2. Nano scale artemisinin algal inhibitor exhibited excellent inhibitory effect.

3. Destruction of algal cells was due to the irreversible damage of cell membrane.

4. Artemisinin microspheres maybe used as a potential candidate for algal control.

5 Graphcal abstract

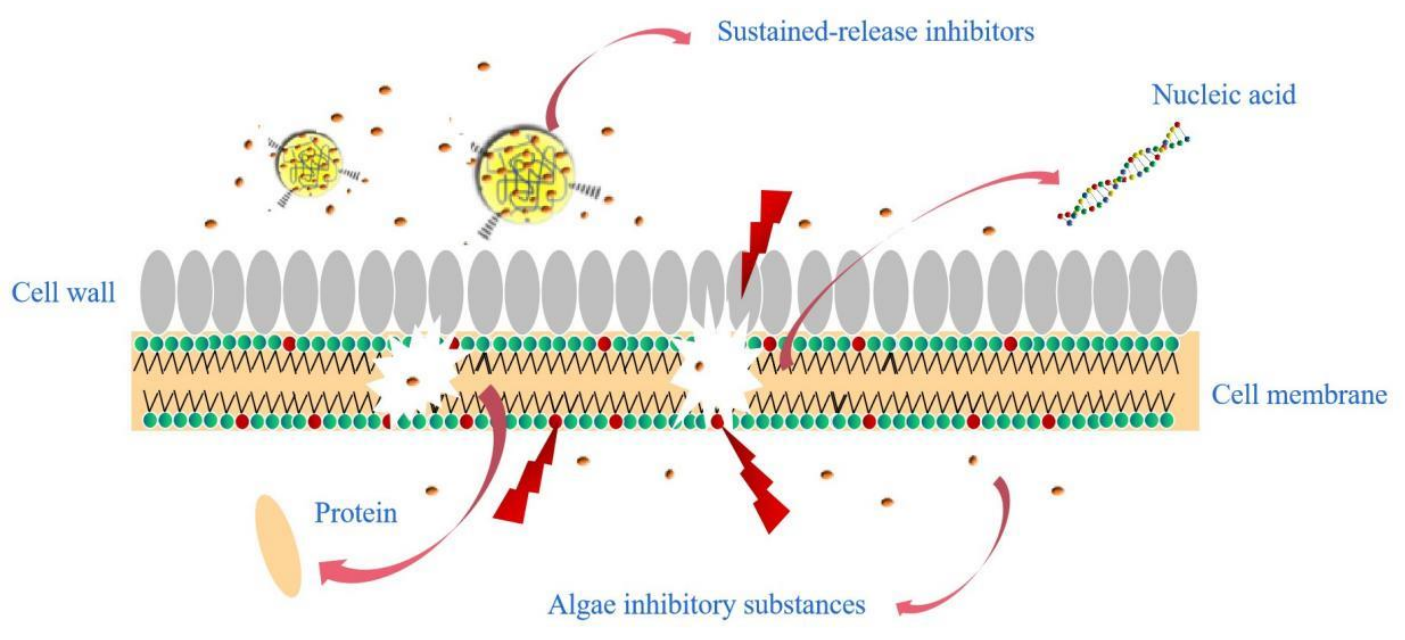




\section{Abstract}

Environment-friendly algaecides based on allelopathy have been widely used to control harmful algal blooms. In this research, micro nano scale artemisinin sustained-release algal inhibitor was prepared, the optimal preparation conditions were explored and the inhibitory mechanism of artemisinin algaecides was perfected. The results showed that when the particle size of artemisinin sustained-release microspheres (ASMs) was 2/10000 of artemisinin sustained-release granules (ASGs), the inhibitory effect was more remarkable. The optimal concentration of ASMs was $0.2 \mathrm{~g} \mathrm{~L}^{-1}$, and the inhibitory effect reached $99 \%$ on the 10th day; The algae density and chlorophyll-a both showed a downward trend, indicating that ASGs and ASMs could promote the degradation of chlorophyll-a; The inhibition rate of ASGs was faster than that of ASMs on the 4th day, and the inhibitory effect of ASMs was more significant after the 5th day. The activities of superoxide dismutase (SOD), peroxidase (POD), catalase (CAT) increased rapidly at first and then decreased, which indicated that ASGs and ASMs caused oxidative damage to Microcystis aeruginosa (M. aeruginos $a$ ) and inhibited the activity of antioxidant enzymes. Furthermore, the content of the oxygen free radical $\left(\mathrm{O}^{2-}\right)$ and malondialdehyde (MDA) continued to rise after the 5th day, the protein, nucleic acid and conductivity in the culture medium increased. These results showed that lipid peroxidation occurred in the algal cell membrane, and the permeability of the membrane increased. In summary, the ASMs had significant continuous inhibitory effect while the ASGs had better short-term effect. The main inhibitory mechanism of artemisinin algaecides is the irreversible damage of cell membrane.

Keywords: Allelochemical; Particle sizes; Optimal manufacture; Inhibitory mechanism; Antioxidant enzyme activity; Cell membrane damage 
1.Introduction

Water eutrophication is a widespread phenomenon and cyanobacteria bloom has become a threat to our water bodies necessitating a corresponding action (Zhao et al. 2010). The ever-increasing Microcystis aeruginosa reproduction rate is the main reason for the outbreak of harmful blooms (Feng et al. 2013, Zhu 2012). The large-scale outbreak of Microcystis aeruginosa leads to the decrease in dissolved oxygen in water, which breaks the stability and balance of the ecosystem (Greenfield et al. 2014, Harke et al. 2016). Therefore, the need to control algae reproduction (Jancula \&Marsalek 2011). Allelopathy has been considered as an important method to solve the algal succession and bloom. Many studies have shown that allelopathy can effectively inhibit the growth of cyanobacteria (Wu et al. 2010, Xiao et al. 2010).

Artemisinin extracted from Artemisia annua $\mathrm{L}$ has been proven to inhibit algae. Artemisinin can cause growth stagnation, injury or death of the receptor organism through affecting cell proliferation, ultrastructure, protein synthesis and biochemical reaction (Guo et al. 2019). Many researchers have begun to pay attention to the allelopathic effect of artemisinin on aquatic organisms. (Ni et al. 2012) isolated and identified artemisinin from Artemisia annua L and confirmed that artemisinin could cause the physiological function disorder of algae cells through algae inhibitory test. (Wu et al. 2013) considered the water productivity around the production area of Artemisia annua might be restricted by the allelopathic effect of artemisinin, and the growth of Chlorella pyrenoidosa and Scenedesmus obliquus was significantly inhibited. (Finaurini et al. 2012) found that the allelopathic effect of artemisinin on water hyacinth reflected in its serious impact on the photosynthetic efficiency of water hyacinth. Therefore, the allelopathic effect of artemisinin on algae provides a new idea for algae inhibition, and its inhibitory mechanism needs to be explored. There is no doubt that allelochemicals affect the biological and biochemical characteristics of algae, and artemisinin is no exception. Most researchers have talked about the influence of allelochemicals on photosynthetic system (Xing et al. 2018, Zhu et al. 2010), cell membrane (Shao et al. 2009) and enzyme activity (Lu et al. 2016, Zhang et al. 2010) when studying the inhibitory mechanism of allelochemicals. The inhibitory 
mechanism of artemisinin's consistency with the inhibitory mechanism of other allelochemicals still needs to be further explored. In addition, it is worth mentioning that adding artemisinin directly into water has the disadvantages of easy loss and is unable to reach the right concentration for algae inhibition. Therefore, embedding allelochemicals into sustained-release particles has become one of the most effective and safe means to inhibit the large-scale propagation of algae (Ni et al. 2018). At the same time, the sustained-release granules have the ability to sustained-term effective release of drugs, which can achieve the effect of long-term effect of algal inhibition and are widely used (Ni et al. 2015).

In a previous research, artemisinin sustained-release algae inhibiting granules (ASGs) were successfully prepared by emulsification method, and their algal inhibitory effect and inhibitory mechanism were explored. In this research, we aim to prepare artemisinin sustained-release algal inhibition microspheres (ASMs) by ion crosslinking method combined with micro nanotechnology, reducing the particle size, swelling rate and increasing the specific surface area of the sustained-release particles. This optimization does not only improve the algae inhibitory effect, but also excludes the use of organic chemical reagents. It is a non-toxic, stable and mild operation method. The main objectives of this paper are to: (1) determine the optimal preparation conditions of artemisinin sustained-release microspheres (ASMs); (2) compare the algal inhibitory effect of two artemisinin sustained-release algae inhibitors; (3) perfect the inhibitory mechanism of artemisinin sustained-release algae inhibitors.

2. Materials and methods

\subsection{Algal cultivation}

M. aeruginosa FACHB-905 was obtained from the Freshwater Algae Culture Collection of the Institute of Hydrobiology (China). It was cultured at Hohai University with sterilized BG-11 medium for one week and grew to logarithmic phase before the test. The algae were cultivated at $25^{\circ} \mathrm{C}$ under $40-60$ $\mathrm{mmol} \cdot$ photons $\cdot \mathrm{m}^{-2} \cdot \mathrm{s}^{-1}(14 \mathrm{~h}$ light $/ 10 \mathrm{~h}$ dark) (Ni et al. 2013), and had to be Oscillated several times a day. 


\subsection{Preparation of ASGs and ASMs}

The drop preparation method was used to prepare ASGs, following the steps of (Ni et al. 2013), which has been described explicitly. The ASMs were produced with Ion crosslinking preparation method, combined with micro nanotechnology. Chitosan and sodium alginate were used as carrier materials to encapsulate artemisinin to prepare novel artemisinin sustained-release algal inhibiting microspheres. The specific steps were shown in Fig. S1. In brief, calcium chloride $\left(6 \mathrm{mg} \mathrm{mL}^{-1}, \mathrm{w} / \mathrm{v}\right)$ solution was slowly dripped (at a mixture speed of 700-1000 rpm) into sodium alginate (1 mg mL $\left.\mathrm{mL}^{-1}, \mathrm{w} / \mathrm{v}, \mathrm{PH} 4.7\right)$ solution to obtain a pregel, which was stirred for 30 min, crushed for $10 \mathrm{~min}$, and then successively dripped the artemisinin solution(10 $\left.\mathrm{mg} \mathrm{mL} \mathrm{m}^{-1}, \mathrm{w} / \mathrm{v}\right)$ and aqueous acetic acid $(1 \%, \mathrm{v} / \mathrm{v})$ solution containing chitosan $(0.6 \mathrm{mg}$ $\mathrm{mL}^{-1}, \mathrm{w} / \mathrm{v}, \mathrm{PH} 5.1$ ) into the pregel, slowly stirring for $60 \mathrm{~min}$, chitosan colloidal microspheres were formed which were then crushed for $1 \mathrm{~min}$. After centrifugating at $12000 \mathrm{rad} / \mathrm{min}$ for $30 \mathrm{~min}$, rinsing several times with distilled water, and freeze drying, the ASMs were then collected. This experiment was carried out with orthogonal test, and the optimal preparing conditions of ASMs were tested by high performance liquid chromatography with a photo diode array (HPLC-PDA).

The artemisinin microspheres were washed three times with double distilled water, grind-mixed with diatomite, and then dissolved in solvent to obtain artemisinin sustained-release solution. HPLC-PDA (Waters 2695 HPLC) was used to determine the artemisinin content of the sustained-release microspheres, and to calculate the encapsulation efficiency based on the initial amount of ASMs. The HPLC-PDA method was performed on a Waters C 18 column. The mobile phase was $0.02 \mathrm{~mol} \mathrm{~L}^{-1}$ $\mathrm{KH}_{2} \mathrm{PO}_{4}$ : acetonitrile $(90: 10 \mathrm{v} / \mathrm{v})$ solution at a flow rate of $1 \mathrm{~mL} \mathrm{~min}^{-1}$, and with a column temperature of $30^{\circ} \mathrm{C}$.

To determine the optimal preparation of ASMs, the concentrations (in $\%$, w/v) of materials mentioned above depended on an orthogonal test. The microspheres size were calculated by dynamic light scattering (DLS) analysis (Mastersizer 3000, UK). The encapsulation efficiency (\%) and drug-loading rate (\%) of the artemisinin was calculated using the following equation: 
where $\mathrm{W}_{1}$ is the measured amount of encapsulated artemisinin in the sustained-release microspheres, and $\mathrm{W}_{0}$ is the initial amount of ASMs.

where $\mathrm{M}_{1}$ is the content of artemisinin in sustained release microspheres, and $\mathrm{M}_{0}$ is the total mass of sustained release microspheres.

\subsection{Algal inhibitory test}

M. aeruginosa in logarithmic growth phase was placed in a $250 \mathrm{ml}$ conical flask,

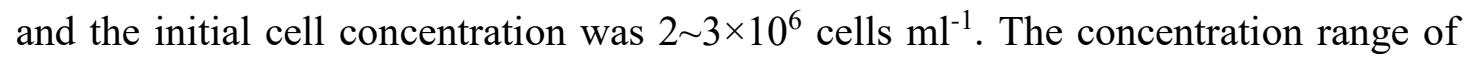
the ASMs was determined by pre-experiment, and then the algae inhibitory experiment was carried out. The blank group (without algae inhibitor) was set up, and the ASMs groups with different concentrations (the dosage of ASMs were $0.1 \mathrm{~g} \mathrm{~L}^{-1}$, $0.2 \mathrm{~g} \mathrm{~L}^{-1}, 0.4 \mathrm{~g} \mathrm{~L}^{-1}, 0.8 \mathrm{~g} \mathrm{~L}^{-1}$ and $1 \mathrm{~g} \mathrm{~L}^{-1}$, respectively). The culture condition was the same as described above in 2.1. The experimental period was 30 days, three parallel groups were set up, and the optical density was measured regularly. By determining the algal inhibition rate of different concentrations of ASMs, the optimal effective dosage of sustained-release microspheres was determined.

\subsection{Inhibitory mechanism studies}

The dosage of ASGs algal inhibitor referred to the previous research (Ni et al. 2013), and the dosage of ASMs algal inhibitor was determined by the results of algae inhibitory test. Three experimental groups were set up in this research: blank control group, ASGs algal inhibitor experimental group and ASMs algal agent experimental group. The three experimental groups were in triplicates, the test period was 30 days. In this research, the initial algal density was $2 \times 10^{6}$ cells $\mathrm{ml}^{-1}$, the optimal dosage of ASGs algal inhibitor was $0.54 \mathrm{~g} \mathrm{~L}^{-1}$, the optimal dosage of ASMs was determined by the results of algae inhibitory test. The content of chlorophyll-a and the activities of antioxidant enzymes (SOD, CAT and POD) were measured every 5 days during the 30-day culture period. The degree of damage on cell membrane was characterized by the content of protein, nucleic acid, MDA (degree of lipid peroxidation), oxygen free 
radical $\left(\mathrm{O}^{2-}\right)$ and the changes in conductivity.

2.5 Algal density and chlorophyll-a content assays

The cell density of $M$. aeruginosa was determined by optical density method. The microscope counting method and the optical density at $680 \mathrm{~nm}$ were used to get a regression equation relating to algal density, that is:

$\mathrm{Y}=169.97 \mathrm{X}-0.351\left(\mathrm{R}^{2}=0.9969\right)$

where $\mathrm{X}$ is the absorbance value and $\mathrm{Y} \times 10^{5}$ cells $\mathrm{mL}^{-1}$ represents the density of algae.

The relative inhibition rate of algae inhibitor release on $M$. aeruginosa is as follows:

$\operatorname{IR}(\%)=\left(1-\mathrm{N} / \mathrm{N}_{0}\right) \times 100 \%$

Where $\mathrm{N}$ is the algal density of treatment group, $\mathrm{N}_{0}$ is the algal density of blank group.

The content of chlorophyll-a was determined by ethanol extraction ( $\mathrm{Li}$ et al. 2019). The absorbance of the extract and blank reference were measured at $665 \mathrm{~nm}$ and $750 \mathrm{~nm}$ respectively. The calculation formula is as follows:

$$
\mathrm{Chl}-\mathrm{a}(\mathrm{mg} / \mathrm{L})=11.93\left(\mathrm{~A}_{665}-\mathrm{A} 750\right)
$$

\subsection{Cell membrane assays}

The content of MDA was determined by thiobarbituric acid (TBA) spectrophotometry (Zhang et al. 2016a). The culture solution was treated with AP-TEMED system and then the concentration of $\mathrm{O}^{2-}$ was determined by measuring its absorbance at $530 \mathrm{~nm}$. The contents of protein and nucleic acid in the culture solution were mainly obtained by measuring the absorbance values of the supernatant at $280 \mathrm{~nm}$ and $260 \mathrm{~nm}$, respectively (Zhang et al. 2016b). Conductivity is mainly measured by conductivity meter.

\subsection{Antioxidant enzymes activities assays}

The total SOD activity was determined by NBT photoreduction method as described by (Charles et al. 1971). The activity of CAT was determined by its ability to decompose $\mathrm{H}_{2} \mathrm{O}_{2}$, and CAT activity was determined according to (Aebi et al. 2010). POD can catalyze the reaction of peroxyphenol and the activity detection method of 
POD referred to (Liu et al. 2010).

2.8 Statistical analysis

All assays were conducted in triplicate. The data in the paper used the average value. All the data were analyzed by one-way ANOVA. SPSS and Origin were used for statistical analysis, in which $\mathrm{p}<0.05$ represents significant difference and $\mathrm{P}<0.01$ represents extremely difference.

3. Results and discussion

\subsection{Optimal manufacture of ASGs and ASMs}

The optimal preparation method of ASGs referred to our team's earlier work in 2013 (Ni et al. 2013), the average particle size of ASGs was $5 \mathrm{~mm}$ and the maximum embedding rate was $52 \%$ by the optimum preparation method. In this research, the optimal preparation method of ASMs was obtained with the same orthogonal test, the optimal preparation concentrations (in $\%, \mathrm{w} / \mathrm{v})$ are as follows: chitosan (0.06), sodium alginate (0.1), calcium chloride (0.6), artemisinin (1). Under the optimal preparation conditions, the microsphere size of ASMs were shown in Fig.1. It is obvious that the microsphere size of ASMs is in the micro nano level, which is far smaller than that of ASGs. According to the experimental data, the average particle size of ASMs was $1189.5 \mathrm{~nm}$, and the embedding rate was $52.4 \%$. It is well known that greatly reduced particle size is beneficial to reduce the swelling rate of the sustained-release algal inhibitor. Therefore, the new preparation method used in this research is conducive to further improve the algae inhibitory effect. 


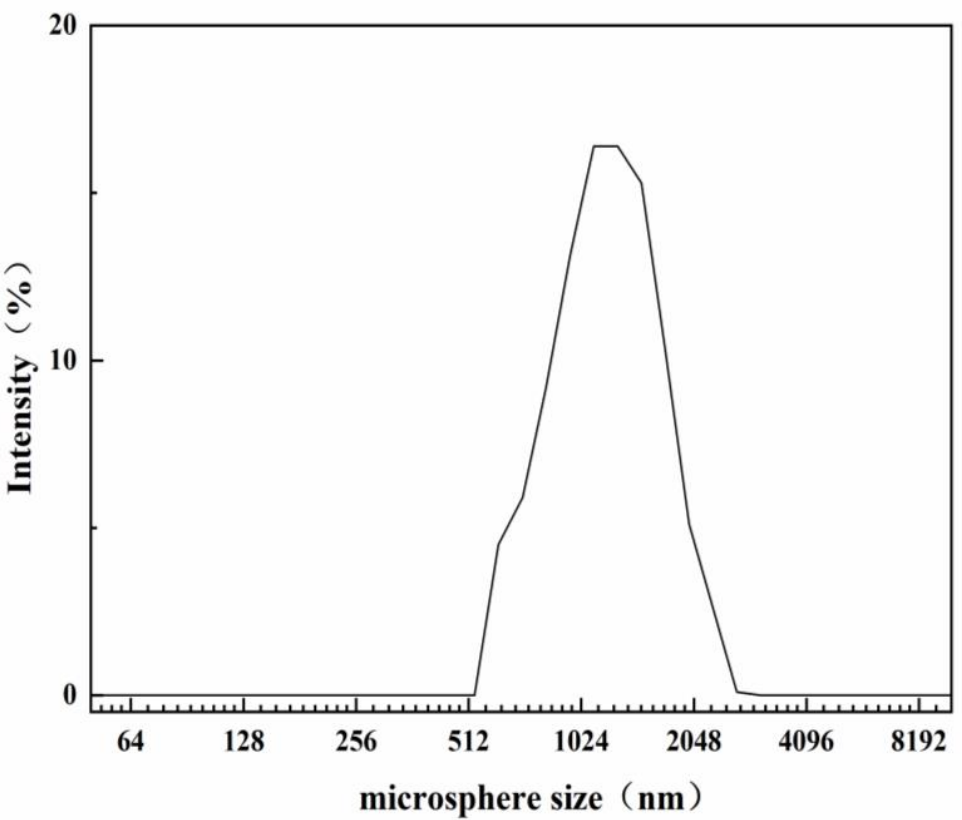

Fig.1. Microspheres size distribution of ASMs under optimal preparation conditions.

3.2 Inhibitory effect of ASMs on M. aeruginosa

M. aeruginosa in logarithmic growth stage was selected to carry out algal inhibitory test under the condition of adding different concentrations of ASMs. The results were shown in Fig.2, the results showed that the inhibitory effect of ASMs with higher concentration on $M$. aeruginosa was more remarkable and the inhibition time was longer than that with low concentration. As shown in Fig.2, the blank control group showed an S-shaped curve growth, showing a normal growth cycle (Li et al. 2010). At the dosage of $0.1 \mathrm{~g} \mathrm{~L}^{-1}$, ASMs showed a transient inhibitory effect on M. aeruginosa. The inhibition rates were all below $30 \%$ after the 2 nd day, and the inhibitory efficiency was only $10.20 \%$ at the end of the experiment (30d). In addition, at the dosage of $0.2 \mathrm{~g} \mathrm{~L}^{-1}$ and $0.4 \mathrm{~g} \mathrm{~L}^{-1}$ showed similar inhibitory effect. The inhibitory effect increased significantly from the 4th day to the 10th day, and maintained high inhibitory efficiency (>99\%) after the 10th day. When the dosage was higher than 0.8 $\mathrm{g} \mathrm{L}^{-1}$, the inhibition rate was as high as $99 \%$ on the 5th day. Considering the perspective of algae inhibitory test and economy, when the concentration of ASMs was $0.2 \mathrm{~g} \mathrm{~L}^{-1}$, the algal inhibitory requirements of the laboratory had been met. As a result, the $0.2 \mathrm{~g} \mathrm{~L}^{-1}$ of ASMs was selected as the optimal algal inhibitory 

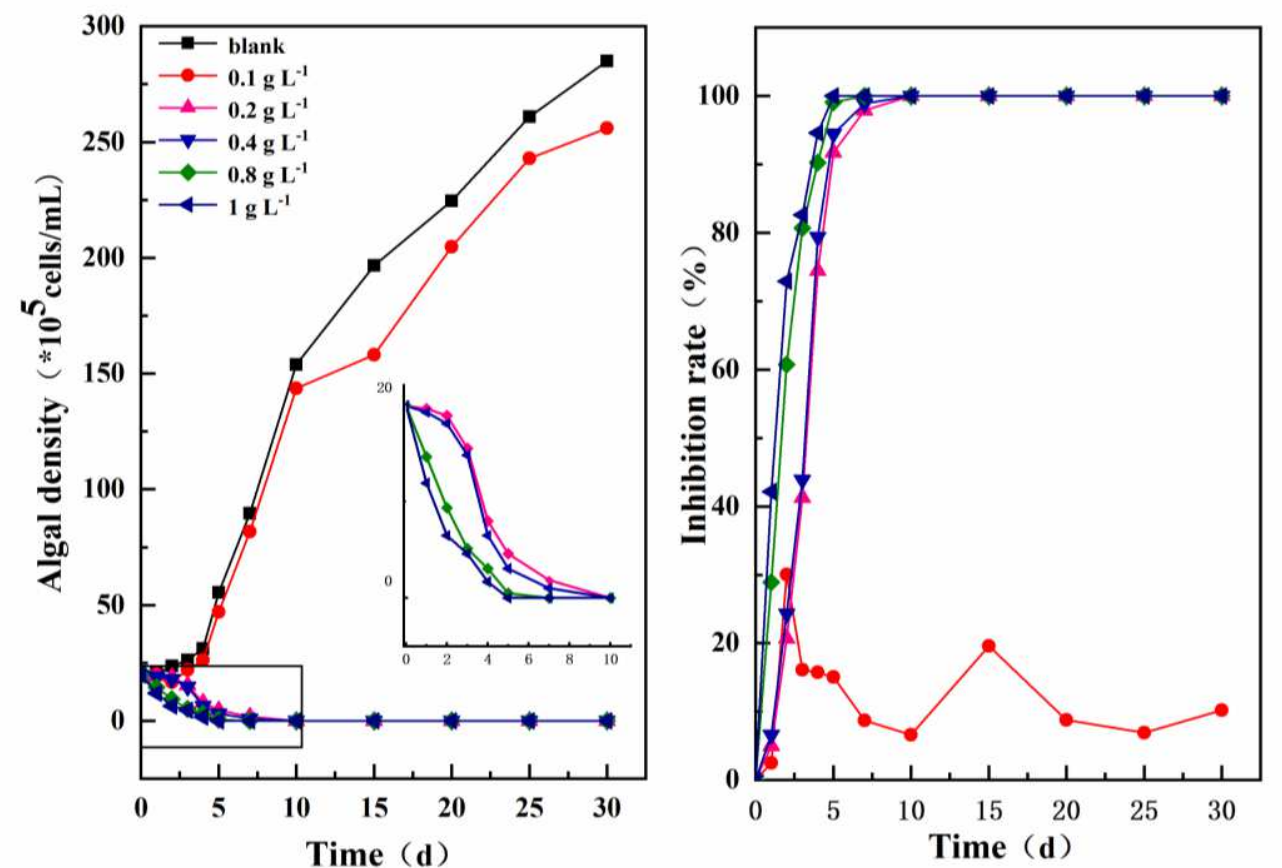

Fig 2 Effects of the different concentration of ASMs on algae density and inhibition rate.

3.3 Effect of ASGs and ASMs on chlorophyll-a

As an important index reflecting the photosynthetic capacity of algae, the content of chlorophyll-a was affected by the growth of algae cells and photosynthesis 239 (Maqbool et al. 2018). In this research, the effects of ASGs and ASMs on the density and chlorophyll-a content of M. aeruginosa were investigated under the optimal algal concentration. The results (Fig.3) were consistent with the results of many researchers (Espinoza-Avalos 2006), the content of chlorophyll-a in blank control group was approximately positively correlated with the density of algae. In addition, the two kinds of algal inhibitors had strong inhibitory effect on the growth of M. aeruginosa, and chlorophyll-a remained at a low level during the whole experiment. At the beginning of the experiment (the first 4 days), ASGs had more obvious inhibitory effect and faster inhibition rate. After the 5th day of the experiment, the algal inhibitory effect and inhibition rate of ASMs shown an obvious reverse phenomenon. After 10 days, both of them showed persistent and high algal inhibitory efficiency while the inhibitory intensity of ASMs was higher. At the end of the experiment (30 
days), M. aeruginosa had no trace of recovery. The reason is that the ASMs had more significant inhibitory effect, which may be because the particle size of ASMs which was far smaller than that of ASGs, coupled with the multi-space structure on its surface, greatly increasing the effective contact area with $M$. aeruginosa; In addition, ASGs easily swell and sink in water, which reduces the contact time with $M$. aeruginosa. It is worth mentioning that in the previous research, the obvious sudden release phenomenon of ASGs in the initial stage may be the real reason for the faster inhibition rate and further effect of ASMs in the initial stage. In general, both algal inhibitors had high efficiency of algae inhibition, but ASMs had a more significant effect on algae inhibition and more destructive to chlorophyll-a.
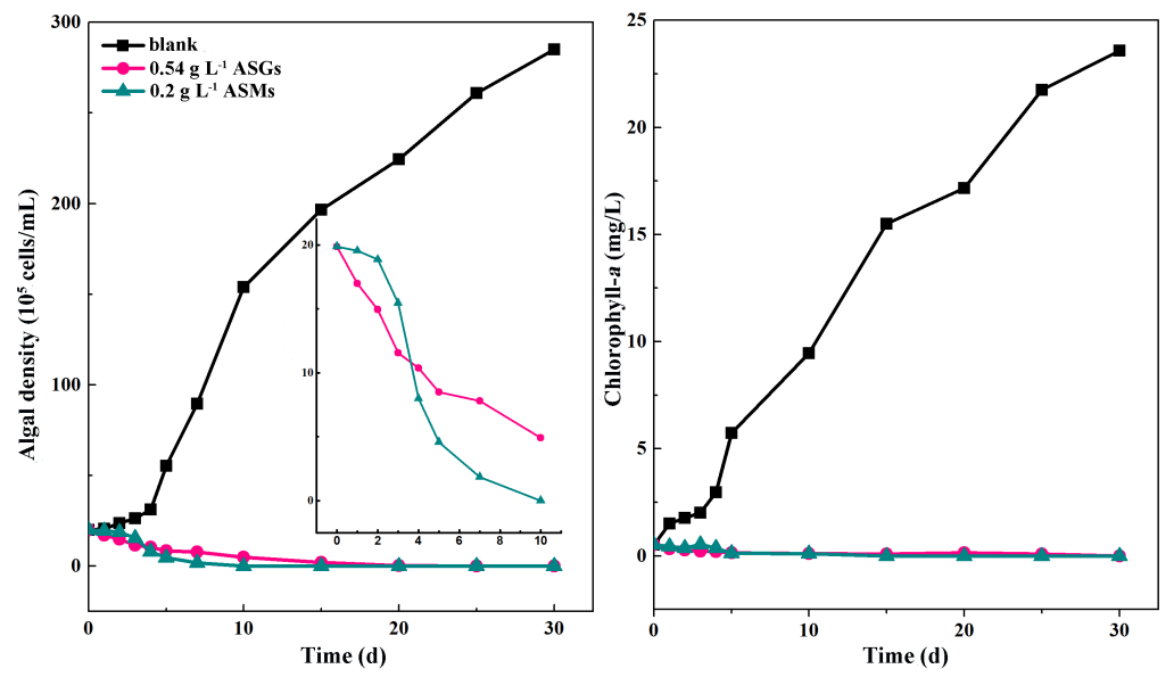

Fig 3. Effects of ASGs and ASMs on algae density and chlorophyll-a of $M$. aeruginosa.

\subsection{Effect of ASGs and ASMs on cell membrane permeability}

Cell membrane is an important structure of cells. Its important components are phospholipid bilayer and protein. It can keep the cell microenvironment stable and has selective permeability function (Jonas et al. 2016). Generally, allelochemicals damage the integrity of cell membrane through allelopathy, reduce its selective permeability function, and make algae cells exude a lot of endolysates (Li et al. 2007). Therefore, we often use the change of cell membrane permeability to characterize the degree of membrane damage. Fig. 4 shows the effect of the two algal inhibitors on the protein 
and nucleic acid content of $M$. aeruginosa. There are the death of some the algae in the experimental process, although in a relatively low range, the proportion is relatively high in the early stage and relatively low in the later stage (Zhou et al. 2009). The content of protein and nucleic acid in the blank control group first decreased and then increased. It was apparent that the contents of protein and nucleic acid in algal solution increased significantly after adding the two kinds of algal inhibitors, and the contents of protein and nucleic acid in ASGs group were higher in the early stage of the experiment. In the middle and later period, it was the opposite. Obviously, the damage effect of ASGs on cell membrane was more rapid and obvious in the early stage, and the ASMs were more dominant in the middle and later stage, which was consistent with the inhibition law of the two algal inhibitors. Therefore, the above results showed that both algal cell membranes were seriously damaged under the continuous stress of these two algal inhibitors, and the decrease of membrane selective permeability resulted in the gradual overflow of protein and nucleic acid from the algae cells to the outside of the cells; during the whole experimental period, the degree damage of algal cells increased with the passage of time, and the damage of ASMs on the cell membrane was more effective and lasting.
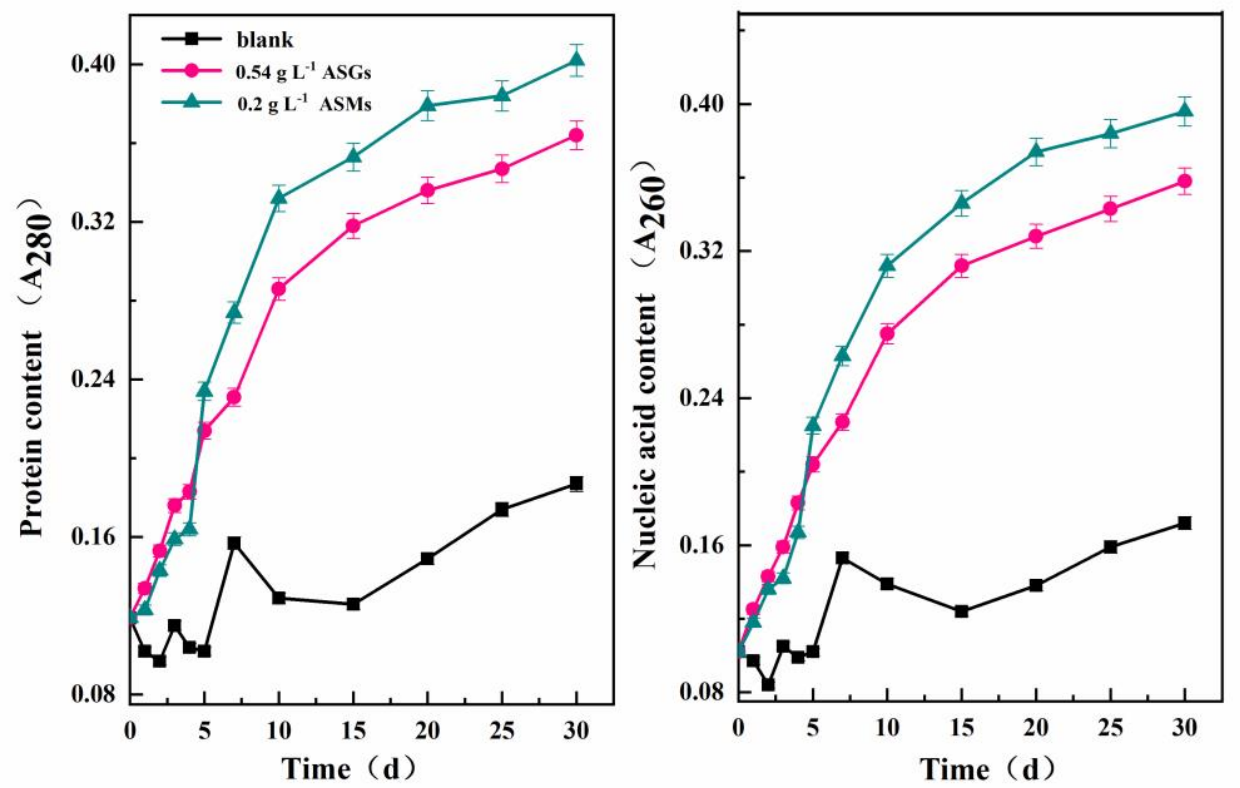

Fig 4 Effects of ASGs and ASMs on protein content and nucleic acid content of $M$. 


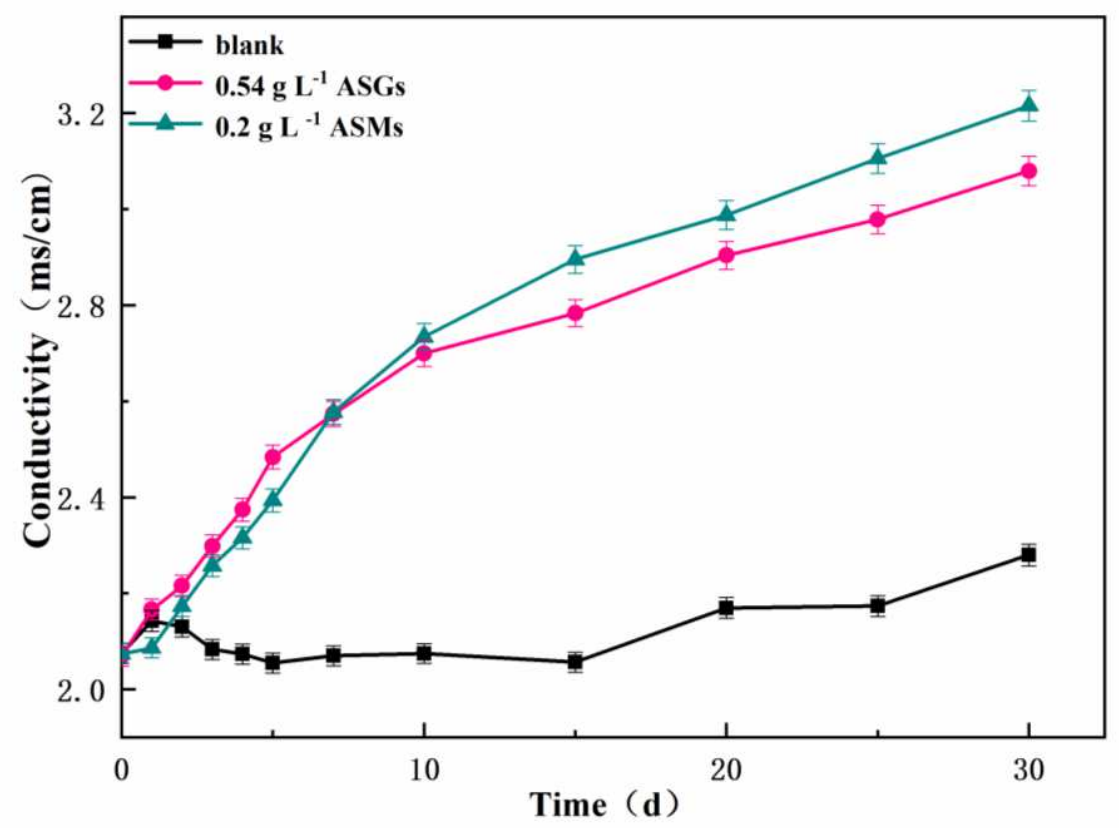

Fig 5 Effects of ASGs and ASMs on conductivity of M. aeruginosa.

Fig 5 shows the change in electrical conductivity under the action of the two kinds of artemisinin sustained-release algal inhibitors. In general, the electrical conductivity of the blank control group did not fluctuate significantly, but increased after adding the two kinds of sustained-release algal inhibitors. On the 2nd day, the conductivity of algal solution was higher than that of blank control group under the action of the two kinds of sustained-release algae inhibitors. After the 7th day, the conductivity of algal liquid under the action of ASMs was gradually higher than that of ASGs. The results showed that under the continuous action of the two kinds of artemisinin sustained-release algal inhibitors, the degree of damage on cell membrane was gradually aggravated, and its permeability was also gradually increased, which led to the leakage of electrolytes including $\mathrm{K}^{+}, \mathrm{PO}_{4}{ }^{2-}$ and other ions in the algae cell to the external environment. These phenomena indicated that artemisinin active substance could cause irreversible damage to cell membrane (Peng et al. 2016), and the damage of ASMs was stronger.

3.5 Oxidative damage

Under the condition of environmental stress, the production and elimination of $\mathrm{O}^{2-}$ in the algal cell system will be out of balance. A large number of $\mathrm{O}^{2-}$ will destroy 
311 the biological macromolecules in the algal cells and cause membrane lipid 312 peroxidation (Huang et al. 2013a, Saed-Moucheshi et al. 2014). MDA is the product 313 of membrane lipid peroxidation. Membrane lipid peroxidation can destroy the 314 structure of cell membrane and make it abnormal (Huang et al. 2013b). The higher the 315 content of MDA, the higher the degree of lipid peroxidation and the more serious 316 damage of cell membrane (Ali et al. 2006). As shown in Fig 6, the contents of $\mathrm{O}^{2-}$ and 317 MDA in the blank control group were almost unchanged, which indicated that the 318 algae did not experience membrane lipid peroxidation and grew normally. In addition, 319 the change in trend for $\mathrm{O}^{2-}$ and MDA content in the two kinds of artemisinin algal 320 inhibitor groups was basically the same, showing different degrees of upward trend, 321 which indicated that the algae cells experienced different degrees of lipid peroxidation 322 after adding the two kinds of sustained-release algal inhibitors, and the algal cells 323 were damaged in different degrees. Specifically, the increase rate of $\mathrm{O}^{2-}$ and MDA content in the ASGs group was higher than that of ASMs group four days prior to the 325 experiment, but it was the opposite after the fifth day. This phenomenon was 326 consistent with the algal inhibitory effect and the above-mentioned law of 327 intracellular solute extravasation. These phenomena all indicated that the algal 328 inhibitory effect of ASGs was better than that of ASMs in a short time while ASMs 329 had better persistent algal inhibitory effect. In addition, it is worth mentioning that, at 330 the point in time when the content of $\mathrm{O}^{2-}$ and MDA in the ASMs group increased 331 significantly, than that of the ASGs group, and the content of $\mathrm{O}^{2-}$ and MDA in the 332 ASMs group was higher than that of the ASGs group. To some extent, this 333 phenomenon indicated that the smaller the particle size of the algal inhibitor, the more 334 favorable the contact between the algal inhibitor and the algal cell, and the algal 335 inhibitory effect was more significant. 

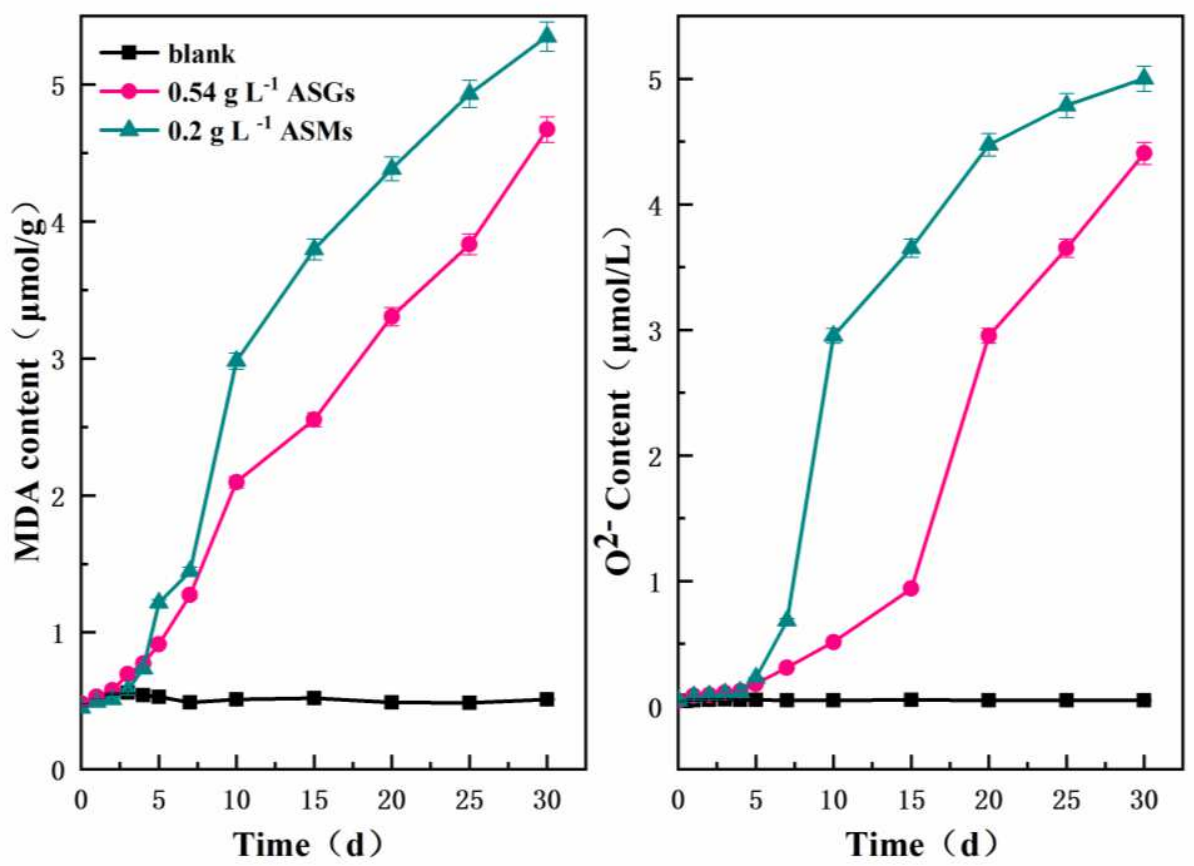

Fig 6 Effects of ASGs and ASMs on MDA and $\mathrm{O}^{2-}$ content of M. aeruginosa.

3.6 Inhibition of antioxidant enzymes activities

Antioxidant system is the protective system of organism against harsh environment. The key antioxidant enzymes are superoxide dismutase (SOD), peroxidase (POD), catalase (CAT) (Gulzar \&Siddiqui 2015). Antioxidant enzymes usually eliminate excessive reactive oxygen species(ROS) to ensure the homeostasis of internal oxidation metabolism. SOD is the key protective enzyme of the body, which can reflect the degree of damage and the ability to resist the adverse environment (Blackhall et al. 2004). CAT and POD play an important role in the antioxidant system of algal cells, which can promote the decomposition of $\mathrm{H}_{2} \mathrm{O}_{2}$ and stabilize the ROS in the organism at a normal level, so as to avoid damage to cells (Tang et al. 2010). 

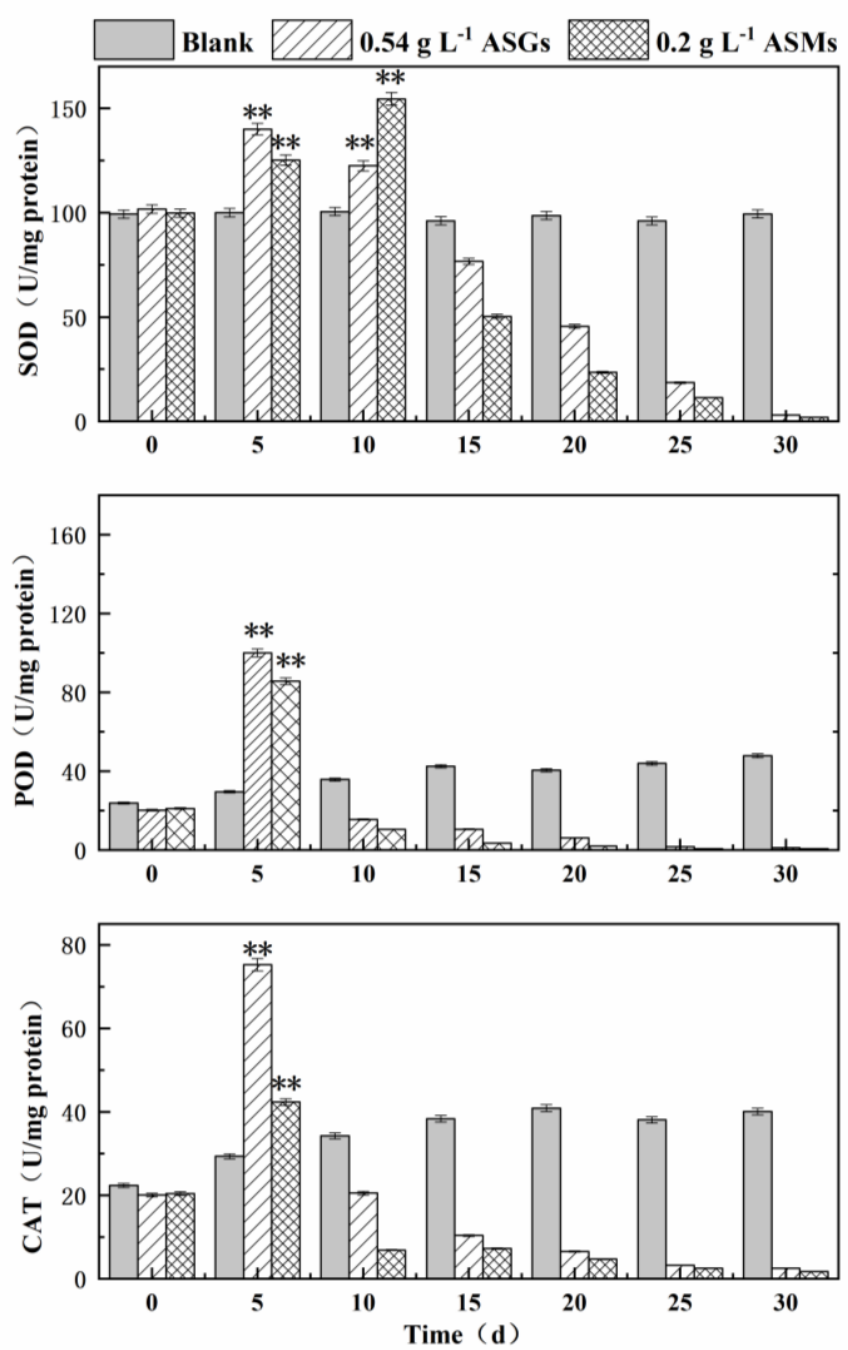

Fig 7 Effects of ASGs and ASMs on activities of SOD, CAT and POD of $M$.

$$
\text { aeruginosa }(* \mathrm{p}<0.05, * * \mathrm{p}<0.01) \text {. }
$$

The activities of SOD, CAT and POD were measured to evaluate the effect of the two kinds of artemisinin sustained-release algal inhibitor on antioxidant enzymes (Fig.7). The activities of SOD, POD and CAT in the two kinds of artemisinin sustained-release algal inhibitor groups showed a trend of rapid increase and then decrease, showing a dynamic change process from induction to inhibition. The SOD activity of the two kinds of artemisinin sustained-release algal inhibitor groups decreased significantly after reaching the maximum value, and the SOD activity was lower than that of the blank control group on the 15 th day. The difference was that the SOD activity of ASGs group reached the maximum value on the 5th day, while the ASMs group reached the maximum value on the 10th day. In addition, the decrease of 
SOD activity in ASMs group was much greater than in ASGs group. With the stress going on, the content of reactive oxygen species in algal cells increased to exceed the capacity of its enzyme activity system, and the activity of SOD began to decrease until it was inactivated (Hejl \&Koster 2004). The activities of POD and CAT reached the maximum on the 5th day, then decreased sharply $(\mathrm{P}<0.01)$ until beyond the detection range.

SOD can convert $\mathrm{O}^{2-\text { into }} \mathrm{H}_{2} \mathrm{O}_{2}$ and $\mathrm{O}_{2}$ specifically to avoid cell injury ( $\mathrm{Ni}$ et al. 2018). This can also explain why the rate of $\mathrm{O}^{2-}$ production is low in the initial stage. CAT and POD can remove excessive hydrogen peroxide in algae cells, so the change in trend for the three antioxidant enzymes was consistent, until the antioxidant enzymes were inactivated. To sum up, under the action of algal inhibitory substances, ROS increased, and the contents of SOD, CAT and POD increased. With the time of inhibition, antioxidant enzymes were gradually inactivated, resulting in damage of algal cells, thus inhibiting the growth of algae ( $\mathrm{Li}$ et al. 2013).

\section{Conclusions}

In summary, the algal inhibitory effect of the two kinds of artemisinin sustained-release algal inhibitors were both significant. The results showed that the optimal concentration of ASMs was $0.2 \mathrm{~g} \mathrm{~L}^{-1}$, and the inhibition rate was as high as $99 \%$ on the 10th day. Under the optimal conditions, the algal inhibitory effect of ASMs with small particle size was better than that of ASGs on the whole, and the ASMs had significant continuous inhibitory effect while ASGs had better short-term effect.

The inhibitory mechanism of ASGs was consistent with that of ASMs. They inhibited the growth of M. aeruginosa by reducing chlorophyll-a content, causing oxidative damage, inhibiting antioxidant enzyme activity and destroying cell membrane. The decrease in chlorophyll-a content in the process of inhibition indicated that both algal inhibitors could inhibit the photosynthesis of algal cells. Under the stress of algal inhibitor, the algal cells were stimulated to produce a large amount of $\mathrm{O}^{2-}$, which resulted in lipid peroxidation of cell membrane and irreversible damage to the permeability of algal cell membrane. At the same time, the production 
392 of a large amount of $\mathrm{O}^{2-}$ can induce the increase of SOD, POD and CAT activities.

393 With the prolongation of inhibition time, ROS produced exceeded its own resistance

394 ability, and finally led to the inactivation of antioxidant enzymes. The accumulation of

395 MDA showed that the cell membrane was damaged to a certain extent, which led to

396 the leakage of substances in the cell, resulting in the increase of protein, nucleic acid

397 and electrical conductivity in the culture medium. The results of this research when

398 compared with the previous research, showed that ASMs had more significant anti

399 algae effect, and the preparation method was more environmentally friendly, and the

400 economic cost was greatly reduced, which provided unlimited possibility for the

401 application of ASMs in controlling red tide in natural lakes in the future.

402 


\section{References}

Aebi H, Wyss SR, Scherz B, SKVARIL F (2010): Heterogeneity of erythrocyte catalase II. Isolation and characterization of normal and variant erythrocyte catalase and their subunits. Febs Journal 48, 137-145

Ali MB, Hahn EJ, Paek KY (2006): Antioxidative responses of in bioreactor liquid cultures. enzyme \& microbial technology 39, 982-990

Blackhall ML, Coombes JS, Fassett R (2004): The relationship between antioxidant supplements and oxidative stress in renal transplant recipients: A review. Asaio Journal 50

Charles, Beauchamp, and, Irwin, Fridovich (1971): Superoxide dismutase: Improved assays and an assay applicable to acrylamide gels. Analytical Biochemistry 44, 276-287

Espinoza-Avalos QY (2006): Reduction of Zooxanthellae Density, Chlorophyll a Concentration, and Tissue Thickness of the Coral Montastraea faveolata (Scleractinia) When Competing with Mixed Turf Algae. Limnology \& Oceanography 51, 1159-1166

Feng Y, Chang X, Zhao L, Li X, Li W, Jiang Y (2013): Nanaomycin A methyl ester, an actinomycete metabolite: Algicidal activity and the physiological response of Microcystis aeruginosa. Ecological Engineering 53, 306-312

Finaurini S, Basilico N, Corbett Y, 'Alessandro SD, Parapini S, Olliaro P, Haynes RK, Taramelli D (2012): Dihydroartemisinin inhibits the human erythroid cell differentiation by altering the cell cycle. Toxicology 300, 57-66

Greenfield, DI, Duquette, Goodson, Keppler, CJ, Williams, SH, Brock, LM (2014): The Effects of Three Chemical Algaecides on Cell Numbers and Toxin Content of the Cyanobacteria Microcystis aeruginosa and Anabaenopsis sp. -

Gulzar A, Siddiqui M (2015): Allelopathic effect of Calotropis procera (Ait.) R. Br. on growth and antioxidant activity of Brassica oleracea var. botrytis. Journal of the Saudi Society of Agricultural Sciences

Guo M, Liu F, Jianzhou L (2019): Advances in Research on the Allelopathic Effects of Artemisinin. Crop Research

Harke, Matthew, J., Steffen, Morgan, M., Gobler, Christopher, J., Otten (2016): A review of the global ecology, genomics, and biogeography of the toxic cyanobacterium, Microcystis spp. Harmful Algae 54, 4-20

Hejl AM, Koster KL (2004): Juglone disrupts root plasma membrane H+-ATPase activity and impairs water uptake, root respiration, and growth in soybean (Glycine max) and corn (Zea mays). Journal of Chemical Ecology 30, 453-71

Huang X, Liang Y, Yang L, Chen R, Yangrui LI (2013a): Effects of Abscisic Acid and Its Biosynthesis Inhibitor on the Activities of Antioxidant System of Sugarcanes Treated by Cold Stress. Journal of South China Agricultural University

Huang Y, Yu B, Yan W, Kong H (2013b): Allelopathic effects of the extracts from an invasive species Solidago canadensis L. on Microcystis aeruginosa. Letters in Applied Microbiology 57 
Jancula D, Marsalek B (2011): Critical review of actually available chemical compounds for prevention and management of cyanobacterial blooms. Chemosphere 85, 1415-1422

Jonas, Van, der, Paal, Erik, Neyts, Christof (2016): Effect of lipid peroxidation on membrane permeability of cancer and normal cells subjected to oxidative stress. Chemical Science

Li FM, Hu HY, Chong YX, Guo MT, Men YJ (2007): [Effects of allelochemical isolated from Phragmites communis on algal membrane permeability]. Huan jing ke xue $=$ Huanjing kexue / [bian ji, Zhongguo ke xue yuan huan jing ke xue wei yuan hui "Huan jing ke xue" bian ji wei yuan hui.] 28, 2453-2456

Li FT, Qi JM, Zhang GY, Lin LH, Fang PP, Tao AF, Xu JT (2013): Effect of Cadmium Stress on the Growth, Antioxidative Enzymes and Lipid Peroxidation in Two Kenaf (Hibiscus cannabinus L.) Plant Seedlings. Journal of Integrative Agriculture 12, 610-620

Li P, Sun X, Yang L, Feifei HE, Wang X (2019): Optimization of extraction protocol of chlorophyll a from algae. CIESC Journal

Li X, Jia-Qi W, Hong-Yang W, Deng-Pan BU, Han HU, Ling-Yun Z (2010): Bovine Mammary Epithelial Cells Culture Methods in vitro and Its Application. Acta Agriculturae Boreali-Sinica

Liu, J., Zhang, X., Sun, Y., Lin, W. (2010): Antioxidative capacity and enzyme activity in Haematococcus pluvialis cells exposed to superoxide free radicals. CHINESE JOURNAL OF OCEANOLOGY AND LIMNOLOGY

Lu Z, Zhang Y, Gao Y, Liu B, Sun X, He F, Zhou Q, Wu Z (2016): Effects of pyrogallic acid on Microcystis aeruginosa: oxidative stress related toxicity. Ecotoxicology \& Environmental Safety 132, 413-419

Maqbool A, Ali S, Rizwan M, Ishaque W, Rasool N, Mzu R, Bashir A, Abid M, Wu L (2018): Management of tannery wastewater for improving growth attributes and reducing chromium uptake in spinach through citric acid application. Environmental Science \& Pollution Research International 25, 10848

Ni L, Acharya K, Hao X, Li S (2012): Isolation and identification of an anti-algal compound from Artemisia annua and mechanisms of inhibitory effect on algae. Chemosphere 88

Ni L, Acharya K, Ren G, Li S, Li Y, Yong L (2013): Preparation and characterization of anti-algal sustained-release granules and their inhibitory effects on algae. Chemosphere 91, 608-615

Ni L, Jie X, Wang P, Li S, Acharya K (2015): Characterization of unsaturated fatty acid sustained-release microspheres for long-term algal inhibition. Chemosphere 120, 383-390

Ni L, Rong S, Gu G, Hu L, Wang P, Li D, Yue F, Wang N, Wu H, Li S (2018): Inhibitory effect and mechanism of linoleic acid sustained-release microspheres on Microcystis aeruginosa at different growth phases. Chemosphere 212, 654-661 
Peng GY, Chen YL, Han YZ, Zhang TT (2016): The inhibitory effect of lactic acid on Microcystis aeruginosa and its mechanisms. Zhongguo Huanjing Kexue/China Environmental Science 36, 1167-1172

Saed-Moucheshi A, Shekoofa A, Pessarakli M (2014): Reactive Oxygen Species (ROS) Generation and Detoxifying in Plants. Journal of Plant Nutrition 37, 1573-1585

Shao J, Wu Z, Yu G, Peng X, Li R (2009): Allelopathic mechanism of pyrogallol to Microcystis aeruginosa PCC7806 (Cyanobacteria): From views of gene expression and antioxidant system. Chemosphere 75, 924-928

Tang B, Shang-Zhong XU, Zou XL, Zheng YL, Qiu FZ (2010): Changes of Antioxidative Enzymes and Lipid Peroxidation in Leaves and Roots of Waterlogging-Tolerant and Waterlogging-Sensitive Maize Genotypes at Seedling Stage. Agricultural Sciences in China 9, 651-661

Wu Y, Zhang S, Zhao H, Yang L (2010): Environmentally benign periphyton bioreactors for controlling cyanobacterial growth. Bioresource Technology 101, 9681-9687

Wu YK, Ling Y, Huang JG, Li LY (2013): Allelopathic effect of artemisinin on green algae. China Journal of Chinese Materia Medica 38, 1349

Xiao X, Ying-Xu C, Xin-Qiang L, Li-Ping L, Xian-Jin T (2010): Effects of Tibetan hulless barley on bloom-forming cyanobacterium (Microcystis aeruginosa) measured by different physiological and morphologic parameters. Chemosphere 81, 1118-1123

Xing C, Yungang WU, Qiao J, Zhang Y (2018): Studies on Allelopathic Inhibition of Aquatic Plant Communities to Algal Bloom. Environmental Science \& Technology

Zhang J, Xie Z, Wang Z, Zhang J, Xie Z, Wang Z (2016a): Oxidative stress responses and toxin accumulation in the freshwater snail Radix swinhoei (Gastropoda, Pulmonata) exposed to microcystin-LR. Environmental Science \& Pollution Research 23

Zhang S, Xia W, Yang X, Zhang T (2016b): [Inhibition effect of aquaculture water of Salvinia natans (L.) All. on Microcystis aeruginosa PCC7806]. Journal of Hygiene Research

Zhang TT, Zheng CY, Wei H, Xu WW, Wang HF (2010): The allelopathy and allelopathic mechanism of phenolic acids on toxic Microcystis aeruginosa. Journal of Applied Phycology 22, 71-77

Zhao YH, Deng XZ, Zhan JY, Xi BD, Lu Q (2010): Progress on preventing and controlling strategies of lake eutrophication in China. Environmental Science \& Technology 33, 92-98

Zhou J, Zeng C, Wang L (2009): STUDY ON CHARACTERISTIC OF ALGAE GROWTH IN TAI LAKE BASED ON NONLINEAR DYNAMIC ANALYSIS. Acta Hydrobiologica Sinica 33, 931-936

Zhu J, Liu B, Jing W, Gao Y, Wu Z (2010): Study on the mechanism of allelopathic influence on cyanobacteria and chlorophytes by submerged macrophyte (Myriophyllum spicatum) and its secretion. Aquatic Toxicology 98, 196-203 
532

533

534

535
Zhu KX, Bi YH, Hu JL, Ai Y, Hu ZY (2012): Characteristics of Microcystis aeruginosa bloom in summer 2008 in Shennong River of Three Gorges Reservoir. Journal of Lake Sciences 


\section{Declarations}

537

- Ethics approval and consent to participate

$538 \quad$ Not applicable

539 - Consent for publication

$540 \quad$ Not applicable

541

- Availability of data and material

542 The datasets analysed during the current study are available from the

$543 \quad$ corresponding author on reasonable request.

544

- Competing interests

545

The authors declare that they have no competing interests.

546

547

548

549

550

551

552

553

554

555

556

- Funding

All sources of funding for the research reported have been declared in Acknowledgements.

- Acknowledgments

This work was supported jointly by the Key Program of the National Natural Science Foundation of China (Grant No.51779079, 51979137), the Natural Science Foundation of Jiangsu Province (Grant No. BK20181313), the Project Funded by the Priority Academic Program Development of Jiangsu Higher Education Institutions (PAPD), and the Top-notch Academic Programs Project of Jiangsu Higher Education Institutions (TAPP). 
559 Zhiyun Jiang: Writing-Original Draft, Formal analysis, Data Curation. Lixiao Ni:

560 Funding acquisition, Conceptualization, Project administration. Xianglan Li:

561 Software, Methodology. Chu Xu: Investigation. Xuqing Chen: Conceptualization,

562 Resources. Shiyin Li: Writing - Review \& Editing. 


\section{Supplementary Files}

This is a list of supplementary files associated with this preprint. Click to download.

- Supplementarymaterial.docx 